\title{
Poliembrionia e aspectos da embriogênese em Tabebuia ochracea (Chamisso) Standley (Bignoniaceae)
}

\author{
MARIA EUGÊNIA COSTA ${ }^{1,5}$, DIANA S. SAMPAIO ${ }^{2,4}$, ADELITA A.S. PAOLI $^{3}$ \\ e SIMONE C.A.L. LEITE ${ }^{4}$
}

(recebido: 26 de dezembro de 2002; aceito: 12 de março de 2004)

\begin{abstract}
Polyembryony and aspects of embryogenesis in Tabebuia ochracea (Chamisso) Standley (Bignoniaceae)). The origin of the extranumerary embryos and the embryogeny of Tabebuia ochracea were analysed. Extranumerary apomictic embryos are of adventitious origin from hypostase cells and from the integument of ovule micropilar region. The embryogeny corresponds to Onagrad type. Among 233 dissected seeds, $81.37 \%$ presented polyembryony and up to seven embryos were detected in a single seed. Sexual and adventitious embryos can develop together in a single seed. Some of the adventitious embryos show severe morphoanatomical anomalies that can affect their development into seedlings.
\end{abstract}

Key words - apomixis, Bignoniaceae, polyembryony, Tabebuia ochracea

RESUMO - (Poliembrionia e aspectos da embriogênese em Tabebuia ochracea (Chamisso) Standley (Bignoniaceae)). A origem dos embriões supranumerários e a embriogenia de Tabebuia ochracea foram analisadas. Embriões supranumerários apomíticos têm origem adventícia a partir de células da hipóstase e do tegumento da região micropilar do óvulo. A embriogenia corresponde ao tipo Onagrado. Das 233 sementes dissecadas 81,37\% apresentaram poliembrionia e foram encontrados até sete embriões em uma mesma semente. Aparentemente, embriões sexuais e adventícios podem se desenvolver juntos, numa mesma semente. Alguns dos embriões adventícios apresentam alterações morfoanatômicas graves que podem prejudicar seu desenvolvimento em plântulas.

Palavras-chave - apomixia, Bignoniaceae, poliembrionia, Tabebuia ochracea

\section{Introdução}

O gênero Tabebuia compreende cerca de 100 espécies de árvores e arbustos popularmente conhecidas como ipês e ocorre do norte do México e Antilhas ao norte da Argentina, estando presente em todos os grandes biomas brasileiros (Gentry 1992). Tabebuia ochracea (Cham.) Standl. é possivelmente o mais comum dos ipês amarelos dos cerrados de Minas Gerais. A embriologia neste gênero ainda é pouco estudada, podendo-se citar apenas os trabalhos realizados com T. rosea (Bert.) DC. (Mehra \& Kulkarni 1985), T. ochracea (Bittencourt Júnior 1996, Gibbs \& Bianchi

1. Universidade Estadual de Ponta Grossa, Setor de Ciências Biológicas e da Saúde, Departamento de Biologia Geral, Av. Carlos Cavalcante, 4748, 84030-900 Ponta Grossa, PR, Brasil.

2. Rua dos Tupis 274, apto. 1101, bairro Centro, 30190-060 Belo Horizonte, MG, Brasil.

3. Universidade Estadual Paulista, Instituto de Biociências, Departamento de Botânica, Av. 24-A, 1515, 13506-900 Rio Claro, SP, Brasil.

4. Pontifícia Universidade Católica de Minas Gerais, Instituto de Ciências Biológicas e da Saúde, Departamento de Ciências Biológicas, Av. Dom José Gaspar, 500, prédio 25, 30535-610 Belo Horizonte, MG, Brasil.

5. Autor para correspondência: mecosta.bh@terra.com.br
1993) e T. pulcherrima Sandw. (Bittencourt Júnior \& Mariath 1997, 2002a, b, c). Em trabalhos de biologia da reprodução, verificou-se a presença de autoincompatibilidade de ação tardia em T. ochracea (Gibbs \& Bianchi 1993, Barros 2001).

A poliembrionia consiste na presença de mais de um embrião em uma mesma semente (Johri 1984). Piazzano (1998) detectou este fenômeno, pela primeira vez, na família Bignoniaceae, ao realizar estudos citogenéticos em Tabebuia chrysotricha (Mart. ex DC.) Standl. e, recentemente, Salomão \& Allem (2001) reportaram sua presença em Tabebuia ochracea, através de estudos de germinação de sementes. Segundo Maheshwari (1950), os embriões supranumerários, quando de natureza esporofítica, podem ser originados a partir de células do nucelo ou dos tegumentos, por clivagem do zigoto ou do proembrião e por diferenciação de células do suspensor. Quando de natureza gametofítica, são derivados de células do saco embrionário diferentes da oosfera. Outra possibilidade é o desenvolvimento de mais de um saco embrionário em um mesmo óvulo.

Segundo Maheshwari (1950), a apomixia pode ser definida como a substituição da reprodução sexual por um processo assexual e pode ser dividida em quatro classes: a primeira, na qual um embrião origina-se 
partenogeneticamente de qualquer célula do megagametófito; a segunda, na qual o megagametófito origina-se de uma célula diplóide, não reduzida meioticamente, cujo embrião tem origem em qualquer célula do gametófito, também por partenogênese; a terceira, na qual os embriões originam-se de tecidos do óvulo que é denominada embrionia adventícia; e a quarta, por sua vez, consiste na formação de bulbilhos ou outros propágulos vegetativos. A segunda e a terceira classes são as mais discutidas e denominadas respectivamente, apomixia gametofítica e esporofítica por Richards (1997), denominações estas adotadas neste trabalho. No entanto, alguns autores, como Carman (1997), restringem o termo apomixia a apomixia gametofítica. A apomixia é geralmente acompanhada pela formação de mais de um embrião em um mesmo óvulo (Fahn 1990). A apomixia esporofítica mostra-se facultativa na maioria dos casos (Richards 1997), podendo ocorrer concomitante à reprodução sexuada.

Goldenberg \& Shepherd (1998) confirmam que as espécies apomíticas possuem maior habilidade em colonizar ambientes inóspitos, apresentando uma distribuição mais ampla que as não apomíticas. Estudos que possibilitem a implantação da apomixia em plantas agrícolas já são amplamente discutidos, prometendo grandes benefícios econômicos e sociais (Grossniklaus et al. 1998, Van Baarlen et al. 1999). Esses interesses certamente serão estendidos a plantas com outras aplicabilidades como as medicinais, as de importância na indústria madeireira, no reflorestamento de áreas degradadas e as ornamentais. Conhecendo-se a origem dos embriões supranumerários em $T$. ochracea e sua freqüência, pode-se inferir a natureza clonal ou sexual das plântulas produzidas. Tal conhecimento tem uso potencial na silvicultura, uma vez que caracteres úteis podem ser facilmente fixados em populações apomíticas (Grossniklaus et al. 1998, Van Baarlen et al. 1999). Dados embriológicos de T. ochracea também podem fornecer subsídios para trabalhos filogenéticos e taxonômicos na família.

O presente trabalho objetivou, por meio de análises anatômicas, detectar a origem dos embriões supranumerários em $T$. ochracea e documentar aspectos de sua embriogênese, contribuindo para os estudos embriológicos da espécie e elucidando o fenômeno da poliembrionia na família Bignoniaceae.

\section{Material e métodos}

Botões florais em pré-antese, flores e frutos em diversos estádios de desenvolvimento foram coletados no estado de
Minas Gerais entre os meses de agosto a outubro nos anos de 1999 e 2000. As coletas foram realizadas em populações da Serra do Cipó (BHCB 68097 e 68098), do município de Matozinhos, na região da Gruta do Baú (BHCB 68100 e 68101) e do município de São Joaquim de Bicas (BHCB 68103).

Sementes maduras e secas foram acondicionadas em sacos de papel e mantidas em geladeira a, aproximadamente, $10^{\circ} \mathrm{C}$. Para a quantificação da poliembrionia e para análises morfológicas dos embriões, 233 sementes da população do município de São Joaquim de Bicas foram embebidas em água destilada por 24 horas e dissecadas sob estereomicroscópio Olympus SZH.

Para o estudo anatômico, ovários e frutos jovens, mais susceptíveis à plasmólise, foram fixados em glutaraldeído $2 \%$, em tampão fosfato $0,1 \mathrm{M}, \mathrm{pH} 6,8$ (Gabriel 1982) e os mais desenvolvidos em FAA50 (Johansen 1940). O material foi desidratado em série butílica, ou etílica (Johansen 1940) e incluído em parafina ou hidroxietilmetacrilato (Tecnovit 7100). Secções seriadas de 5 a $12 \mu \mathrm{m}$ de espessura foram obtidas em micrótomo de rotação. Os cortes foram corados com safranina e azul de astra $0,5 \%$ (modificado de Bukatsch 1972) ou azul de toluidina $0,05 \%$, em tampão acetato $0,1 \mathrm{M}, \mathrm{pH} 4,4$ (Feder \& O'Brien 1968). Para a realização das fotomicrografias e dos desenhos sob câmara clara, utilizou-se fotomicroscópio Olympus BHS-BH-2 e estereomicroscópio Olympus SZH, respectivamente.

\section{Resultados}

Ocorrência da poliembrionia - Dentre as populações analisadas, apenas uma das da Serra do Cipó (BHCB 68098) não apresentou poliembrionia. As demais populações possuíam frutos com sementes mono e poliembriônicas. Das 233 sementes dissecadas, 81,37\% apresentaram poliembrionia e foram encontrados até sete embriões em uma mesma semente. Aparentemente, embriões sexuais e adventícios podem se desenvolver juntos, numa mesma semente, até a maturidade da mesma.

Óvulo - Os óvulos de T. ochracea são anátropos, unitegumentados, tenuinucelados (figura 1) e o saco embrionário é do tipo Polygonum. No óvulo do botão em pré-antese, com saco embrionário imaturo binuclear, o nucelo é representado pela epiderme nucelar e pela hipóstase. A primeira é constituída por uma camada de células, que circunda o saco embrionário e está adjacente à hipóstase em sua extremidade calazal (figura 1). A hipóstase é uma região diferenciada na calaza, localizada entre o feixe funicular e o saco embrionário, cujas células possuem paredes espessas e citoplasma denso (figuras 1-4) apresentando um conteúdo envolto por pequenos vacúolos que se cora de púrpura, quando se utiliza o azul de toluidina. Nas 
paredes das células da hipóstase de T. ochracea não foi detectada a presença de lignina sob luz polarizada.

O saco embrionário tetranuclear apresenta aspecto piriforme devido ao seu desenvolvimento progressivo principalmente na região micropilar, onde as células da epiderme nucelar e do endotélio foram degeneradas. Dessa forma, o saco embrionário fica delimitado na região calazal pela hipóstase e por vestígios da epiderme nucelar, lateralmente, por parte do endotélio e na região micropilar, pelo tegumento (figuras 2, 4).

A penetração do tubo polínico no óvulo é porogâmica. A sinérgide degenerativa, de coloração mais escura, mostra-se lateral ao zigoto (figuras 4,5 ) e seus vestígios são detectados até os primeiros estádios de desenvolvimento do endosperma.

Diferenciação de células precursoras de embriões adventícios (PEA) - Em ovários nos quais tubos polínicos já alcançaram a região placentária, podem ser observadas células adjacentes ao saco embrionário provindas da hipóstase (figura 3) e, ocasionalmente, da região micropilar do tegumento (figuras 4, 5), expandindo-se para o seu interior e adquirindo formato tubular. Trata-se das células precursoras de embriões adventícios (PEA). As PEA provindas da região micropilar do tegumento, são distintas das sinérgides devido a sua polaridade, formato tubular e semelhança com as PEA da hipóstase e, distintas do zigoto por este ser visível ao seu lado e apresentar uma extremidade calazal mais arredondada que corresponde à morfologia remanescente da oosfera (figuras 4, 5).

Em algumas células da hipóstase, as paredes adjacentes ao saco embrionário tornam-se delgadas indicando que este processo antecede o alongamento das PEA desta região. As PEA possuem um grande vacúolo em sua extremidade basal, restringindo o citoplasma à apical (figuras 5,6). Nota-se, em algumas PEA, a formação de um outro vacúolo menos conspícuo em sua extremidade apical (figura 7). Algumas das PEA da hipóstase alcançam o aparelho oosférico ao se alongarem intensamente após sua diferenciação. As PEA permanecem sem sofrer divisões até que o endosperma torne-se multicelular (figuras 8,9).

Foi observado que num mesmo óvulo no qual já estão presentes proembriões em estádio globular, células da hipóstase podem ainda estar diferenciando-se em precursoras de embrião adventício (figura 10). O desenvolvimento dos embriões adventícios mostra-se bastante semelhante ao do embrião zigótico, podendo ser diferenciados uns dos outros devido ao seu posicionamento no interior da semente. Entretanto, a distinção entre embriões originados do tegumento da região micropilar e os zigóticos torna-se dificultada devido ao seu igual posicionamento (figuras 11, 12).

Aspectos da embriogênese - $\mathrm{O}$ endosperma sofre suas primeiras divisões seguidas de citocinese e o zigoto alonga-se em direção à extremidade calazal do saco embrionário tornando-se tubular (figura 8). Ele mantém a mesma polaridade da oosfera apresentando um vacúolo basal conspícuo (figuras $8,13 \mathrm{~A}$ ). O zigoto penetra no endosperma e permanece sem sofrer divisões até que o último apresente-se multicelular (figuras 8,9).

As etapas da embriogênese que se seguem basearam-se em observações de embriões zigóticos e adventícios. A primeira divisão do zigoto ou das PEA ocorre no sentido transversal, originando uma célula basal (cb) e outra apical (ca). Foi observado um proembrião linear de três células, das quais a mais basal (ci) apresenta-se vacuolada e as demais (m e ca) apresentam conteúdo citoplasmático denso (figura 13B). A célula apical ( $\mathrm{ca}$ ) divide-se longitudinalmente, originando duas células denominadas ca' (figura 13C) que, posteriormente, sofrem outra divisão longitudinal, não concomitante, perpendicular à primeira, formando um quadrante (figuras 13D, 13D'). As células do quadrante, por sua vez, dividem-se transversalmente resultando num octante (figura 13E). Neste último estádio, são observadas três células mais basais em um só estrato (figura 13E), das quais a mais apical (d), derivada da divisão transversal de $\mathrm{m}$, divide-se longitudinalmente (figura $13 \mathrm{~F}$ ). A célula $\mathrm{f}$, também derivada de $\mathrm{m}$, divide-se transversalmente originando as demais células do suspensor. Aparentemente, a célula mais basal do suspensor (ci) não se divide, alongandose intensamente (figura $13 \mathrm{~F}$ ) e fazendo com que o proembrião penetre no endosperma.

As células do octante dividem-se periclinalmente originando a protoderme (figura 13F). Posteriormente, as células mais internas do octante dividem-se anticlinal e periclinalmente enquanto as células da protoderme sofrem divisões anticlinais acompanhando o crescimento do embrião (figura 13F). As duas células resultantes da divisão longitudinal da célula d (figura 13F) dividem-se transversalmente originando dois estratos bicelulares, $\mathrm{d}$ e d', sendo o primeiro o mais apical (figura 13G). As células de cada estrato (d e d') dividem-se longitudinalmente, originando duas camadas de quatro células que contribuem para a formação do ápice radicular.

O proembrião globular achata-se (figura $13 \mathrm{H}$ ) e adquire simetria bilateral com a diferenciação dos cotilédones, o eixo hipocótilo-radícula apresenta 

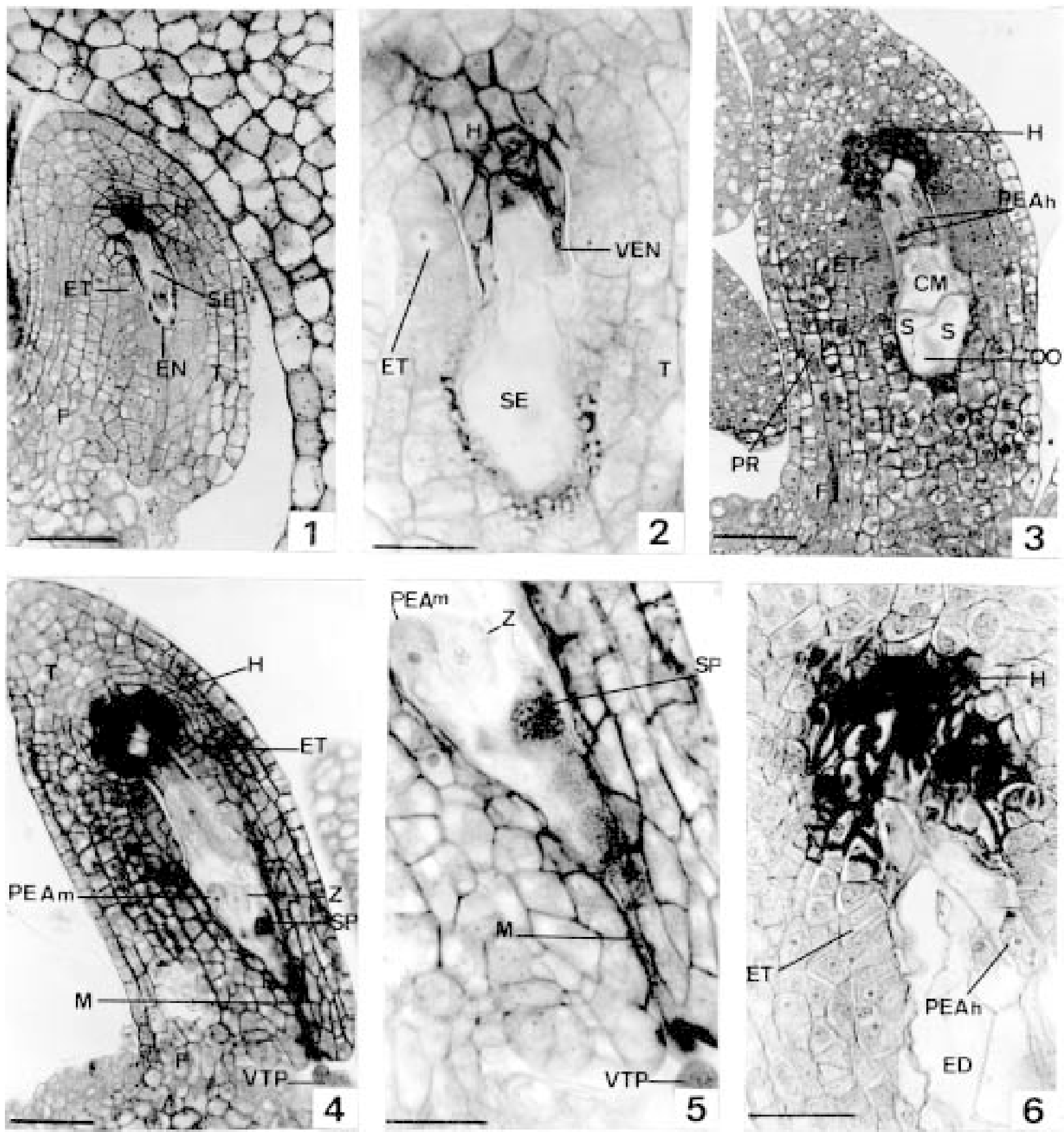

Figuras 1-6. Óvulos e semente de Tabebuia ochracea em secção longitudinal. 1. Óvulo de botão em pré-antese com saco embrionário imaturo binuclear, epiderme nucelar ainda presente. 2. Óvulo de botão em pré-antese com saco embrionário imaturo tetranuclear, epiderme nucelar e endotélio degenerados na região micropilar. 3-5. Óvulo de flor pós-antese já polinizada. 3. Diferenciação de células precursoras de embrião adventício da hipóstase (PEAh) antes mesmo do alongamento do zigoto. 4. Diferenciação de uma célula precursora de embrião adventício da região micropilar (PEAm) ao lado do zigoto e da sinérgide penetrada pelo tubo polínico. 5. Detalhe da PEAm. 6. Semente de Tabebuia ochracea em desenvolvimento. PEAh alongando-se e tornando-se tubular com um grande vacúolo basal. $(\mathrm{CM}=$ célula média; $\mathrm{ED}$ = endosperma; $\mathrm{EN}$ = epiderme nucelar; $\mathrm{ET}=$ endotélio $; \mathrm{F}=$ funículo $; \mathrm{H}=$ hipóstase $; \mathrm{M}=$ micrópila $; \mathrm{OO}=$ oosfera $; \mathrm{PEAh}=$ célula precursora de embrião adventício da hipóstase; $\mathrm{PEAm}=$ célula precursora de embrião adventício da região micropilar; $\mathrm{PR}=$ procâmbio; $\mathrm{S}=$ Sinérgide; $\mathrm{SE}=$ saco embrionário; $\mathrm{SP}=$ sinérgide penetrada pelo tubo polínico; $\mathrm{T}=$ tegumento; $\mathrm{VEN}=$ vestígio de epiderme nucelar; $\mathrm{VTP}=$ vestígio de tubo polínico; $\mathrm{Z}=$ zigoto $)$. Barras $=25 \mu \mathrm{m}(2,5,6), 50 \mu \mathrm{m}(1,3,4)$. 
procâmbio conspícuo (figura 13I). No ápice radicular podem-se observar vestígios do suspensor, as células iniciais, a coifa e a protoderme (figura 13I).

A célula mais basal do suspensor (ci) dos embriões adventícios originados da hipóstase parece ancorar-se nas paredes do haustório calazal (figura 14) e a daqueles originados da região micropilar, bem como a do zigoto, ancora-se, provavelmente, em células do tegumento da micrópila.

Em sementes monoembriônicas, os embriões maduros apresentam coloração branca opaca, são retos, com eixo hipocótilo-radícula curto, plúmula nãodiferenciada e cotilédones bilobados justapostos. Em sementes poliembriônicas, foram considerados típicos aqueles embriões com as mesmas características supracitadas, podendo apresentar algumas alterações na morfologia dos cotilédones. Nessas sementes, também, observaram-se embriões de coloração arroxeada, com dimensões inferiores às dos típicos, apresentando suas células plasmolisadas (figura 15), o que lhes confere uma consistência membranácea.

Na população do município de São Joaquim de Bicas, foram observados embriões considerados anômalos, bem menores que os demais, com cotilédones foliáceos de coloração amarronzada que apresentam tricomas tectores simples ou estrelados e tricomas glandulares, além de elementos traqueais com espessamento secundário (figura 16).

Os diferentes tipos de embriões encontrados nas sementes poliembriônicas (típico, de consistência membranácea e anômalo) estão representados na figura 17.

Detectaram-se sementes nas quais estava presente apenas um embrião de morfologia típica em posição "invertida", ou seja, com o eixo hipocótilo-radícula voltado para a região calazal, indicando sua natureza adventícia e, ainda, sementes possuindo apenas um ou mais embriões anômalos. Também foram encontrados, em sementes poliembriônicas, embriões imaturos em estágio globular e cordiforme.

\section{Discussão}

Uma das populações estudadas da Serra do Cipó (BHBC 68098) não apresentou poliembrionia, semelhante ao observado por Swamy (1948), que notou variações desse comportamento para diferentes raças de Spiranthes cernua (L.) Rich. Isso sugere que essa população de T. ochracea seja constituída por uma subespécie ou raça distinta das demais, o que pode ser reforçado pelas observações de Gibbs \& Bianchi (1993) que documentaram os primeiros estádios após a fecundação, em $T$. ochracea, e não reportaram a presença de células precursoras de embriões adventícios. Além disso, Goldenberg \& Shepherd (1998) sugerem que populações de espécies amplamente dispersas possam variar no nível de ploidia e no grau de apomixia que apresentam. Salomão \& Allem (2001) encontraram um baixo número de embriões por semente (dois a quatro) e uma baixa freqüência de sementes poliembriônicas (3\%), em T. ochracea, através de germinação de sementes. Acreditamos que as diferenças encontradas neste trabalho, em relação aos dados obtidos por Salomão \& Allem (2001), podem ser justificadas por alguns embriões serem inviáveis e só detectados através da dissecação de sementes e, ainda, pelas possíveis variações populacionais quando se trata da porcentagem de sementes poliembriônicas.

As células precursoras de embriões adventícios (PEA) foram identificadas, nos óvulos, por serem distintas das células pertencentes ao saco embrionário do tipo Polygonum, por seu posicionamento no interior do óvulo e por sua semelhança morfológica ao zigoto. Este último aspecto é reconhecido por Batigina (1999)

Figures 1-6. Ovules and seed of Tabebuia ochracea in longitudinal section. 1. Ovule of pre-antheses bud with binuclear unripe embryonic sack, nucelar epidermis still present. 2. Ovule of pre-antheses bud with tetranuclear unripe embryonic sack, degenerate nucelar epidermis and endothelium in the micropylar region. 3-5. Ovule of post-antheses flower already pollinated. 3. Differentiation of adventitious embryo precursory cells of the hypostase (PEAh) even before the zygote elongation. 4. Differentiation of an adventitious embryo precursory cell of the micropylar region (PEAm) beside the zygote and the synergide penetrated by the pollinic tubes. 5. Detail of PEAm. 6. Seed of Tabebuia ochracea in development. PEAh elongating and becoming tubular with a large basal vacuole. $(\mathrm{CM}=$ medium cell; $\mathrm{ED}=$ endosperm; $\mathrm{EN}=$ nucelar epidermis; $\mathrm{ET}=$ endothelium; $\mathrm{F}$ = funiculus; $\mathrm{H}=$ hypostase $; \mathrm{M}=$ micropyle; $\mathrm{OO}=$ egg cell; $\mathrm{PEAh}=$ adventitious embryo precursory cell of the hypostase; $\mathrm{PEAm}=$ adventitious embryo precursory cell of the micropylar region; $\mathrm{PR}=$ procambium; $\mathrm{S}=$ synergide; $\mathrm{SE}=$ embryonic sack; $\mathrm{SP}=$ synergide penetrated by the pollinic tube; $\mathrm{T}=$ integument; $\mathrm{VEN}=$ vestige of nucelar epidermis; $\mathrm{VTP}=\mathrm{vestige}$ of pollinic tube; $Z=$ zygote $)$. Bars $=25 \mu \mathrm{m}(2,5,6), 50 \mu \mathrm{m}(1,3,4)$. 

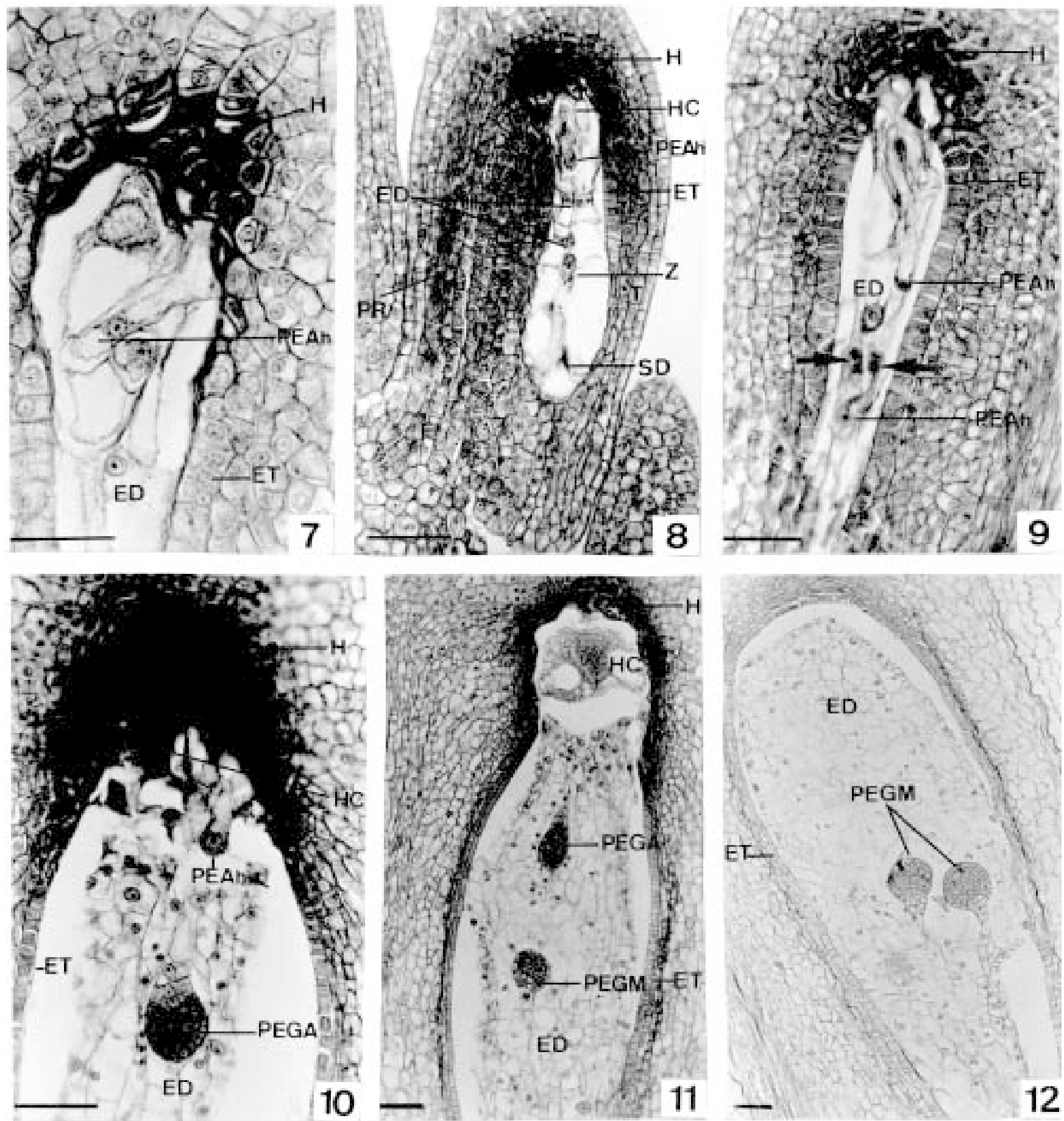

Figuras 7-12. Sementes de Tabebuia ochracea em desenvolvimento em secção longitudinal. 7. Célula precursora de embrião adventício derivada da hipóstase (PEAh) alongando-se e tornando-se tubular com um vacúolo basal e outro apical. 8. Zigoto e PEAh em semente com endosperma de oito células. 9. Duas PEAh e duas células alongadas, localizadas na região micropilar, uma de provável origem zigótica e outra precursora de embrião adventício derivada do tegumento da região micropilar (setas). 10. PEAh alongando-se em uma semente com um proembrião globular adventício originado da hipóstase (PEGA). 11. Proembrião globular provindo da região micropilar (PEGM) de origem zigótica ou adventícia e proembrião globular adventício originado da hipóstase (PEGA). 12. Dois proembriões globulares provindos da região micropilar (PEGM), sendo, provavelmente, um zigótico e outro adventício derivado do tegumento dessa região. ( $\mathrm{ED}=$ endosperma; $\mathrm{ET}=$ endotélio; $\mathrm{F}=$ funículo; $\mathrm{H}=$ hipóstase; HC = haustório calazal; PEAh = célula precursora de embrião adventício derivada da hipóstase; PEGA = proembrião globular adventício originado da hipóstase; $\mathrm{PEGM}=$ proembrião globular provindo da região micropilar; $\mathrm{PR}=$ procâmbio; $\mathrm{SD}=$ sinérgide degenerativa; $\mathrm{T}=$ tegumento; $\mathrm{Z}=$ zigoto $)$. Barras $=25 \mu \mathrm{m}(7), 50 \mu \mathrm{m}(8-12)$. 
como o primeiro indício significativo de que estas células sejam precursoras dos embriões adventícios.

Em T. ochracea, o zigoto e a maioria dos embriões adventícios iniciam suas divisões concomitantemente e seu desenvolvimento inicial apresenta-se bastante semelhante. Esse fato pode ser justificado pelas células precursoras de embriões adventícios se alongarem para a cavidade do saco embrionário, tornando-se tubulares, e apresentarem a mesma polaridade observada no zigoto, com o vacúolo voltado para a extremidade basal da célula. Este fato parece não ser comum, uma vez que na literatura são reportados casos em que se formam calos ou brotos multicelulares nos tecidos esporofíticos do óvulo, que posteriormente se deslocam para o interior do saco embrionário (Maheshwari 1950).

As PEA apresentam-se especialmente abundantes e de fácil visualização na região calazal e são decorrentes do alongamento de células da hipóstase. Essas células são bastante diferenciadas, entretanto, fazem parte de um tecido originalmente totipotente que é o nucelo, o que justifica sua capacidade de dar origem às PEA. Devido à sua localização, as células da hipóstase podem participar ativamente na translocação de nutrientes para o saco embrionário em desenvolvimento (Swamy 1941, Tilton 1980), o que também pode influenciar no alto número de PEA aí encontradas. $O$ fato de não haver deposição de lignina nas células da hipóstase é menos comum (Tilton 1980), entretanto isto favorece a sua diferenciação em PEA. É complicado tentar explicar o fato de essas células se diferenciarem tão vigorosamente em embriões adventícios estando localizadas nas adjacências do haustório calazal do endosperma, que, segundo Mehra \& Kulkarni (1985), mostra-se extremamente agressivo. O conteúdo envolto por pequenos vacúolos, de cor púrpura quando corado pelo azul de toluidina, presente em quase todas as células da hipóstase pode ser o mesmo verificado por Tilton (1980) em Ornithogalum caudatum Ait., identificado como algum tipo de carboidrato diferente do amido que, no caso de $T$. ochracea, pode suprir alguma energia para a diferenciação das PEA derivadas da hipóstase.

A origem nucelar ou tegumentar de embriões adventícios é largamente reportada na literatura (Maheshwari 1950, Baker 1960, Duncan 1970, Koltunow et al. 1995, Gupta et al. 1996, Mendes-daGlória et al. 2001), no entanto, não há citações de sua origem a partir da hipóstase. As células precursoras de embriões adventícios da região micropilar são menos freqüentes e aparentemente menos viáveis que as da hipóstase.

Os tipos de embriogenia para dicotiledôneas diferem-se quanto aos planos das primeiras divisões do zigoto e quanto à sua seqüência, observando-se os produtos da célula terminal do embrião bicelular e a participação da célula basal na formação do embrião (Johri 1984). O significado evolutivo desses tipos não está totalmente estabelecido, porém eles têm sido utilizados para fins taxonômicos (Esau 1985). A embriogenia de $T$. ochracea é do tipo Onagrado, de acordo com o sistema de classificação de Johansen (1950), como também foi observado em diversos trabalhos com a família Bignoniaceae, o de Souèges (1940) para Catalpa kaempferi Sieb. \& Zucc., de Swamy (1941) para Bignonia megapotamica Spreng., de Ghatak (1956) para Oroxylum indicum (L.) Vent. e de Mehra \& Kulkarni (1985) para Tabebuia rosea, Millingtonia hortensis L., Dolichandrone falcata Seem., Heterophragma adenophyllum (Wall. ex G. Don) Seem. ex Benth. \& Hook. e Stereospermum chelonoides (L.f.) DC. Johri et al. (1992) consideraram este tipo como o representativo da família. O tipo Onagrado caracteriza-se pelo plano

Figures 7-12. Seeds of Tabebuia ochracea in development in longitudinal section.7. Adventitious embryo precursory cell derived from the hypostase (PEAh) elongating and becoming tubular with a basal and an apical vacuole. 8. Zygote and PEAh in seed with an eight-cell endosperm. 9. Two PEAh and two elongated cells located in the micropylar region, one with probable zygotic origin and other, an adventitious embryo precursory cell derived from the integument of the micropylar region (arrows). 10. PEAh elongating in a seed with an adventitious globular proembryo originated from the hypostase (PEGA). 11. Globular proembryo come from the micropylar region (PEGM) with zygotic or adventitious origin and adventitious globular proembryo originated from the hypostase (PEGA). 12. Two globular proembryos come from the micropylar region (PEGM), being, probably, one zygotic and the other adventitious derived from the integument of this region. $(\mathrm{ED}=$ endosperm; $\mathrm{ET}=$ endothelium; $\mathrm{F}=$ funiculus $\mathrm{H}=$ hypostase $\mathrm{HC}=$ chalazal haustorium; $\mathrm{PEAh}=$ adventitious embryo precursory cell derived from the hypostase; PEGA = adventitious globular proembryo originated from the hypostase; $\mathrm{PGM}=$ Globular proembryo come from the micropylar region; $\mathrm{PR}=$ procambium; $\mathrm{SD}=$ degenerative synergide; $\mathrm{T}=$ integument $\mathrm{Z}=$ zygote). $\mathrm{Bars}=25 \mu \mathrm{m}(7), 50 \mu \mathrm{m}(8-12)$. 

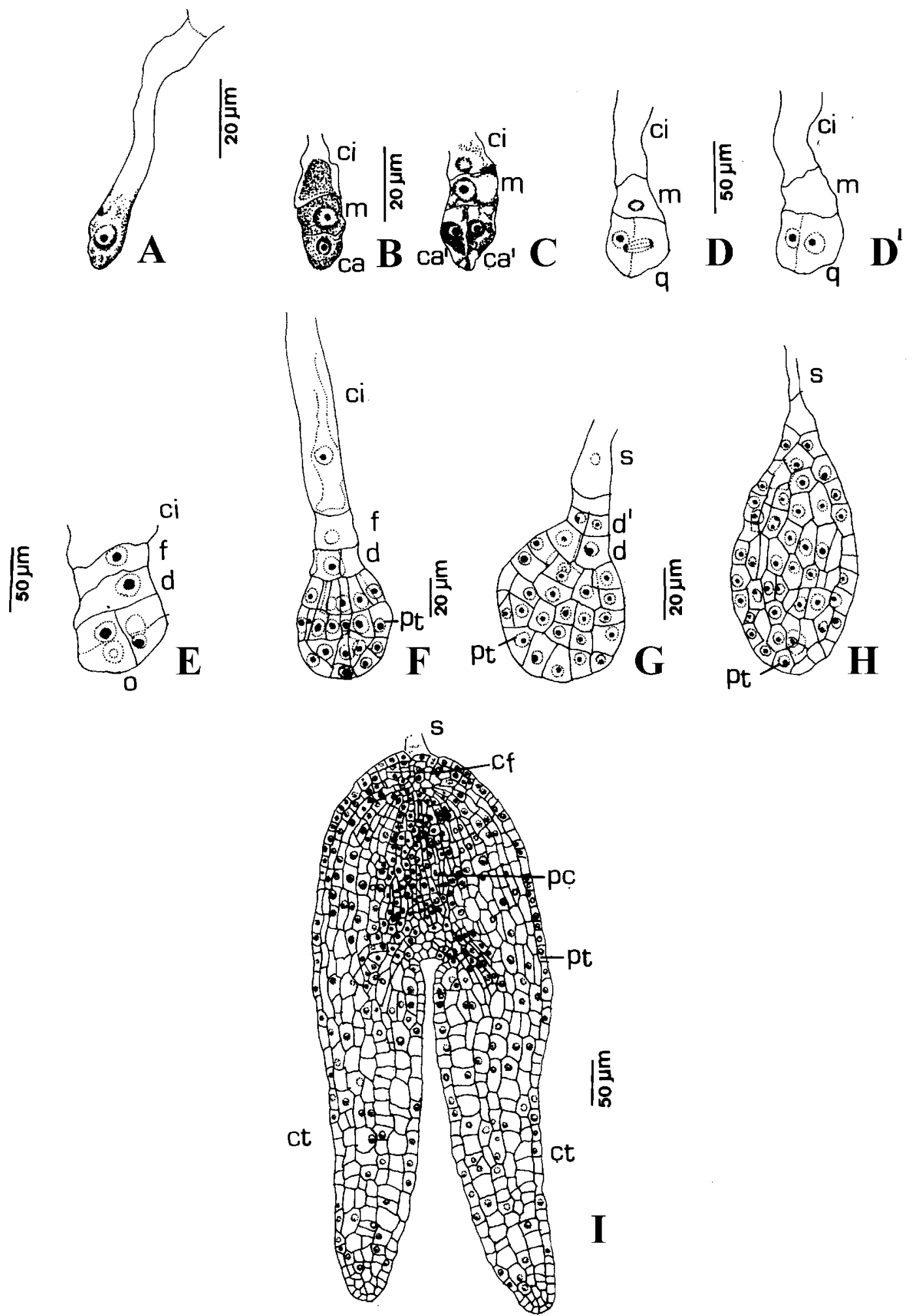

Figura 13. Aspectos da embriogênese de Tabebuia ochracea baseados na observação de embriões zigóticos e adventícios. A. zigoto. B-H. proembriões. Em D e D' cada desenho representa secções do mesmo proembrião. I. Embrião em estádio de torpedo. ( $\mathrm{ca}$ = célula apical derivada da primeira divisão do zigoto; ca' = célula resultante da divisão longitudinal de ca; $\mathrm{cf}=$ coifa; $\mathrm{ci}=$ célula mais basal derivada da divisão transversal de $\mathrm{cb}$ (célula basal derivada da primeira divisão do zigoto); $\mathrm{ct}=$ cotilédone; $\mathrm{d}$ = célula mais apical resultante da divisão transversal de m; d' = células mais basais resultantes da divisão transversal de d; $\mathrm{f}$ = célula mais basal resultante da divisão transversal de $\mathrm{m} ; \mathrm{m}=$ célula mais apical derivada da divisão transversal de cb; $\mathrm{o}=$ octante $; \mathrm{pc}=$ procâmbio $; \mathrm{pt}=$ protoderme $; \mathrm{q}=$ quadrante $; \mathrm{s}=$ suspensor $)$. 

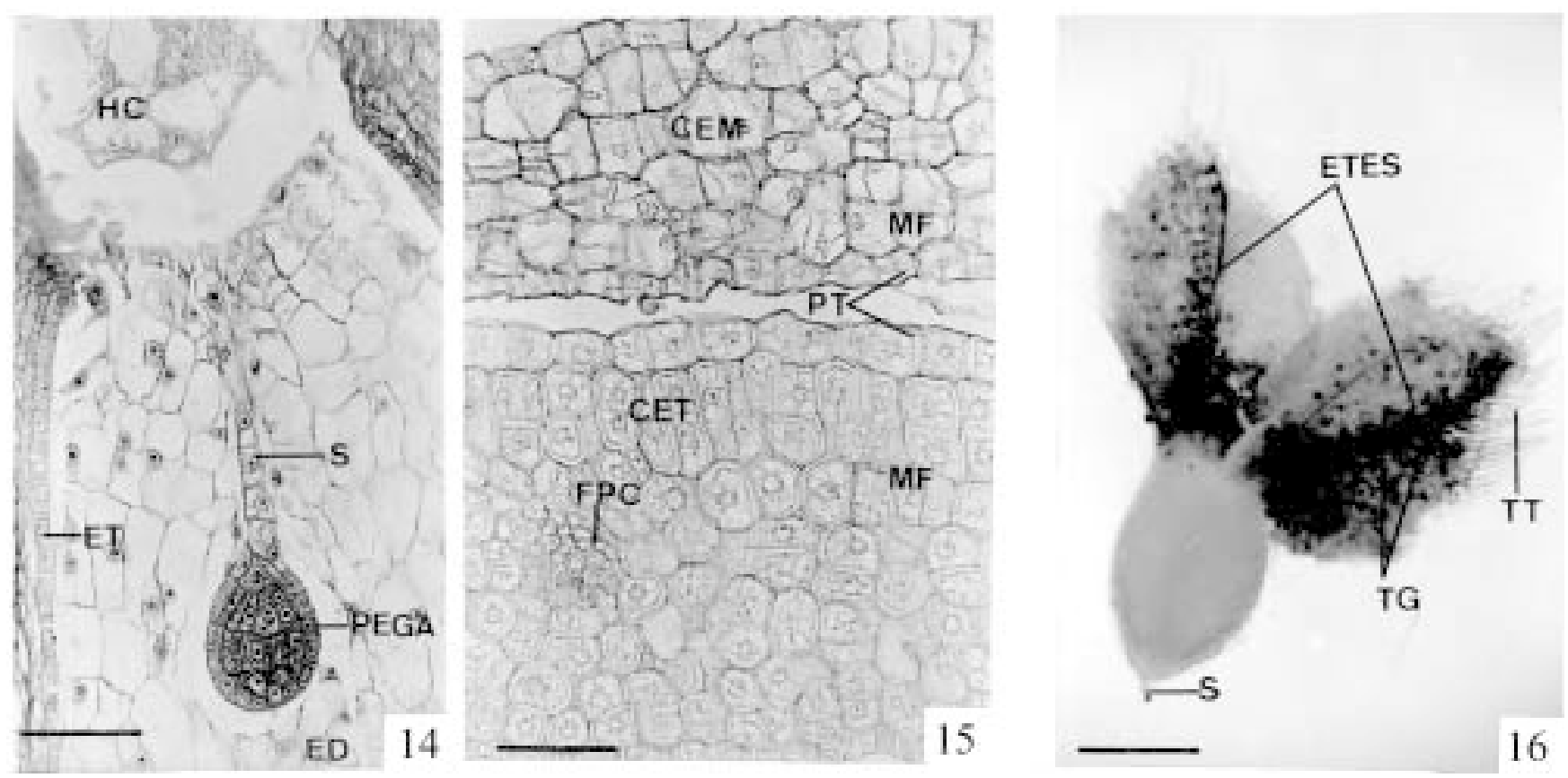

Figuras 14-16. Tabebuia ochracea 14. Semente em desenvolvimento em secção longitudinal. Proembrião globular adventício (PEGA) provindo da hipóstase com suspensor possuindo de cinco a seis células. 15. Cotilédones de um embrião típico e de um membranáceo em secção transversal. 16. Embrião adventício anômalo de uma semente madura dissecada. (CEM = cotilédone de embrião membranáceo; $\mathrm{CET}=$ cotilédone de embrião típico; $\mathrm{EBM}=$ embrião membranáceo; $\mathrm{EBT}=$ embrião típico; $\mathrm{ED}=$ endosperma; $\mathrm{ET}$ = endotélio; ETES = elemento traqueal com espessamento secundário; $\mathrm{FPC}$ = feixe procambial; $\mathrm{HC}=$ haustório calazal; $\mathrm{MF}=$ meristema fundamental; PEGA = proembrião globular adventício originado da hipóstase; $\mathrm{PT}=$ protoderme; $\mathrm{S}=$ suspensor; $\mathrm{TG}=$ tricomas glandulares; $\mathrm{TT}=$ tricomas tectores $)$. Barras $=50 \mu \mathrm{m}(14,15), 500 \mu \mathrm{m}(16)$.

Figures 14-16. Tabebuia ochracea. 14. Seed in development in longitudinal section. Adventitious globular proembryo (PEGA) come from the hypostase with suspensor having from five to six cells. 15. Cotyledons of a typical embryo and of a membranaceous one in transverse section. 16. Anomalous adventitious embryo of a dissected ripe seed. (CEM $=$ cotyledon of membranaceous embryo; $\mathrm{CET}=$ cotyledon of typical embryo; $\mathrm{ED}=$ endosperm; $\mathrm{ET}=$ endothelium; $\mathrm{ETES}=$ tracheal element with secondary thickening; $\mathrm{FPC}=$ procambial bundle; $\mathrm{HC}=$ chalazal haustorium; $\mathrm{MF}=$ fundamental meristem; $\mathrm{PEGA}=$ adventitious globular proembryo originated from the hypostase; $\mathrm{PT}=$ protoderm; $\mathrm{S}=$ suspensor; $\mathrm{TG}=$ glandular trichomes; $\mathrm{TT}=$ simple trichomes). $\operatorname{Bars}=50 \mu \mathrm{m}(14,15), 500 \mu \mathrm{m}=(16)$.

longitudinal da primeira divisão da célula terminal do proembrião e pela participação da célula basal na formação do corpo do embrião.

Segundo Duncan (1970), em Bombacopsis glabra (Pasq.) A. Robyns, 20 dias após a polinização, o zigoto apresenta os primeiros sinais de divisão e, no mesmo estádio, células isoladas do nucelo também começam a se dividir formando massas que se desenvolvem como embriões adventícios. Similarmente, em T. ochracea, as primeiras divisões do zigoto e das PEA são concomitantes, o que pode ser justificado por ambos necessitarem dos mesmos recursos disponíveis no endosperma que, neste estádio, já se encontra multicelular.

Figure 13. Aspects of embryogenesis of Tabebuia ochracea based on the observation of zygotic and adventitious embryos. A. Zygote. B-H. Proembryos. In D and D', each drawing represents sections of the same proembryo. I. Embryo in torpedo stage. $(\mathrm{ca}=$ apical cell derived from the first zygote division; $\mathrm{ca}$ ' = cell resulting from the longitudinal division of $\mathrm{ca}$; $\mathrm{cf}=\mathrm{root}$ $\mathrm{cap}$; $\mathrm{ci}$ = more basal cell derived from the transverse division of $\mathrm{cb}$ (basal cell derived from the first zygote division); $\mathrm{ct}=$ cotyledon; $\mathrm{d}=$ more apical cell resulting from the transverse division of $\mathrm{m} ; \mathrm{d}$ ' = more basal cells resulting from the transverse division of $\mathrm{d} ; \mathrm{f}=$ more basal cell resulting from the transverse division of $\mathrm{m} ; \mathrm{m}=$ more apical cell derived from the transverse division of $\mathrm{cb}$; $\mathrm{o}=$ octant $; \mathrm{pc}=$ procambium; $\mathrm{pt}=$ protoderm $; \mathrm{q}=$ quadrant $; \mathrm{s}=$ suspensor $)$. 
A presença de apenas um embrião adventício em algumas sementes pode ser justificada pela não fecundação da oosfera ou pela degeneração do embrião zigótico, devido à competição com o adventício. Uma outra possibilidade seria a ocorrência de autoincompatibilidade de ação tardia, já verificada em populações de T. ochracea (Gibbs \& Bianchi 1993, Barros 2001), que permitiria a germinação do tubo polínico e impediria a formação de embriões sexuados, mas não do endosperma necessário para o desenvolvimento dos embriões apomíticos. Tais casos são desfavoráveis sob o ponto de vista evolutivo, uma vez que diminuem a variabilidade genética da espécie. Embriões imaturos, que são encontrados em sementes maduras, representam uma perda energética para a planta-mãe, já que não estão aptos a germinar. Sua presença é explicada pela diferenciação contínua de células da hipóstase em PEA até o estádio globular dos primeiros embriões adventícios diferenciados. Com isso, pode-se concluir que o estímulo para a diferenciação de PEA está presente até estádios avançados do desenvolvimento da semente. Koltunow et al. (1995) também observaram embriões em diferentes estádios

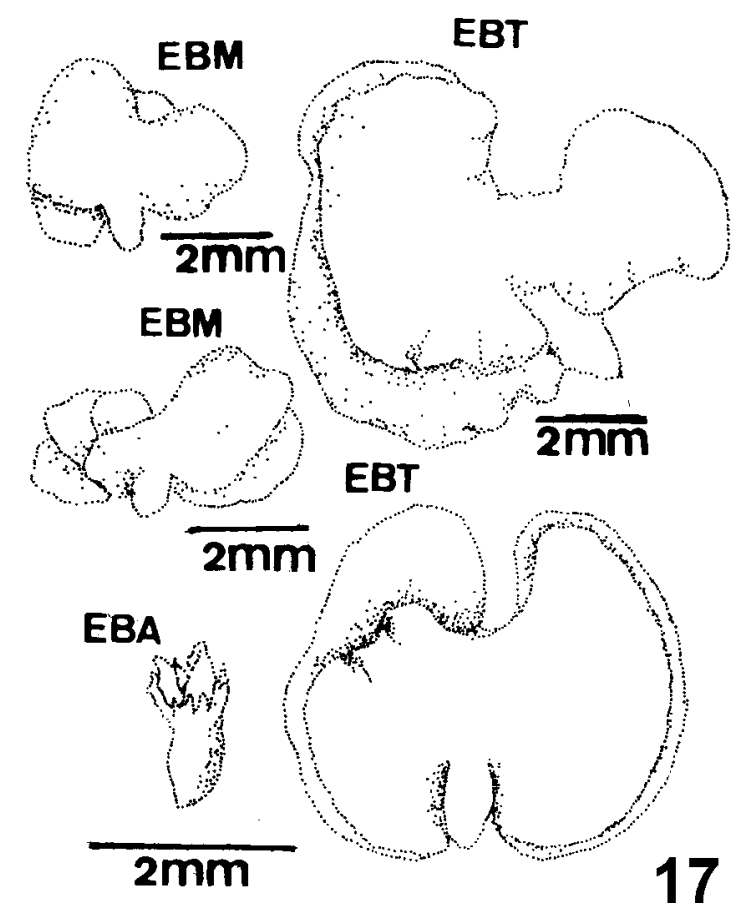

Figura 17. Tabebuia ochracea, cinco embriões de uma mesma semente poliembriônica dissecada. (EBA = embrião anômalo; $\mathrm{EBM}=$ embrião membranáceo; $\mathrm{EBT}=$ embrião típico).

Figure 17. Tabebuia ochracea, five embryos from the same dissected ripe polyembryonic sees. $(\mathrm{EBA}=$ anomalous embryo; EBM membranaceous embryo; $\mathrm{EBT}=$ typical embryo). de desenvolvimento em sementes maduras de Citrus sinensis (L.) Osbeck cv. Valencia, entretanto parece que não há uma diferenciação contínua de embriões nucelares e sim uma assincronia num estádio de desenvolvimento avançado dos embriões.

Em T. ochracea, a ocorrência da poliembrionia associada ao elevado número de sementes por fruto deve ser fator que compensa a baixa conversão de flores em frutos, devido à escassez de recursos maternos, ao aborto de pistilos pobremente polinizados e à menor frequiência de visitantes, quando comparada à $T$. aurea (Manso) Benth. \& Hook.; além de compensarem os danos feitos por Trigona spinipes (Fabricius, 1793) aos frutos de T. ochracea (Barros 2001). Essa mesma autora verificou a ausência de apomixia em $T$. ochracea através de polinizações controladas, entretanto ela considerou como apomixia o desenvolvimento de embriões sem a ocorrência de polinização, um estímulo necessário ao desenvolvimento dos embriões adventícios nas populações em estudo.

As alterações morfológicas dos cotilédones de embriões zigóticos ou adventícios provavelmente são causadas pela competição por espaço no interior da semente, semelhante ao observado em Citrus por Mendes-da-Glória et al. (2001). Os mesmos autores verificaram que as alterações na morfologia e tamanho dos cotilédones não prejudicam a conversão dos embriões em plântulas. Estudos preliminares de quantificação da poliembrionia através de sementes dissecadas e germinadas de T. ochracea apontam para a inviabilidade de embriões de consistência membranácea e daqueles de morfoanatomia anômala (D.S. Sampaio \& M.E. Costa, dados não publicados). Corroborando tais observações, trabalhos sobre embriogênese somática têm mostrado uma relação positiva entre aberrações morfológicas e a baixa conversão de embriões somáticos em plantas (Mendesda-Glória et al. 2001).

Dada a origem tegumentar e da hipóstase dos embriões supranumerários conclui-se que estes são de origem apomítica esporofítica. Uma vez que a apomixia pode ser diretamente relacionada ao caráter poliplóide (Oliveira et al. 1992, Richards 1997, Goldenberg \& Shepherd 1998) e que já foi detectada a presença de poliembrionia concomitante ao caráter tetraplóide $(2 \mathrm{n}=80)$ em $T$. chrysotricha (Piazzano 1998), é possível que também ocorra poliploidia na espécie em estudo. T. chrysotricha e T. ochracea são as únicas espécies da família Bignoniaceae nas quais a poliembrionia já foi reportada, o que reforça sua conhecida proximidade taxonômica (Gentry 1992), além 
de corroborar a idéia de Goldenberg \& Shepherd (1998), para a família Melastomataceae, de que a apomixia esteja mais relacionada à taxonomia e filogenia do que com o hábitat.

Agradecimentos - Ao Dr. Nelson Sabino Bittencourt Jr. pela revisão criteriosa do trabalho, sugestões, ensinamentos e constante estímulo. Ao Departamento de Botânica da UFMG e à Dra. Rosy Mary dos Santos Isaias pelo suporte técnico e uso das dependências do laboratório de Anatomia Vegetal. Aos revisores anônimos que possibilitaram uma grande melhoria na qualidade do texto. Ao PROBIC-PUC-MG pela bolsa de iniciação científica de uma das autoras (Diana $\mathrm{S}$. Sampaio) e pelo financiamento deste.

\section{Referências bibliográficas}

BAKER, H.G. 1960. Apomixis and polyembryony in Pachira oleaginea (Bombacaceae). American Journal of Botany 47:296-302.

BARROS, M.G. 2001. Pollination ecology of Tabebuia aurea (Manso) Benth. \& Hook. and Tabebuia ochracea (Cham.) Standl. (Bignoniaceae) in Central Brazil cerrado vegetation. Revista Brasileira de Botânica 24:255-261.

BATIGINA, T.B. 1999. Embryogenesis and morphogenesis of zygotic and somatic embryos. Russian Journal of Plant Physiology 46:774-788.

BITTENCOURT JÚNIOR, N.S. 1996. Microsporogênese e etapas da ontogenia do gametófito masculino de Tabebuia ochracea (Cham.) Standley (Bignoniaceae). Acta Botanica Brasilica 10:9-23.

BITTENCOURT JÚNIOR, N.S. \& MARIATH, J.E.A. 1997. Ontogenia dos estratos parietais da antera de Tabebuia pulcherrima Sandw. (Bignoniaceae). Acta Botanica Brasilica 11:9-30.

BITTENCOURT JÚNIOR, N.S. \& MARIATH, J.E.A. 2002a. Pollen development of Tabebuia pulcherrima Sandwith (Bignoniaceae) from meiosis to anthesis. Boletim de Botânica da Universidade de São Paulo 20:17-29.

BITTENCOURT JÚNIOR, N.S. \& MARIATH, J.E.A. 2002b. Ovule ontogeny of Tabebuia pulcherrima Sandwith (Bignoniaceae): megasporogenesis and integument development. Revista Brasileira de Botânica 25:103-115.

BITTENCOURT JÚNIOR, N.S. \& MARIATH, J.E.A. 2002c. Ovule ontogeny of Tabebuia pulcherrima Sandwith (Bignoniaceae): embryo sac development. Revista Brasileira de Botânica 25:117-127.

BUKATSCH, F. 1972. Bemerkungen zur doppelfärbung Astrablau-Safranin. Mikrofosmos 61:255.

CARMAN, J.G. 1997. Asynchronous expression of duplicate genes in angiosperms may cause apomixis, bispory, tetraspory, and polyembryony. Biological Journal of Linnean Society 61:51-94.
DUNCAN, E.J. 1970. Ovule and embryo ontogenesis in Bombacopsis glabra (Pasq.) A. Robyns. Annals of Botany 34:677-683.

ESAU, K. 1985. Anatomía vegetal. $3^{\text {rd }}$ ed. Omega, Barcelona.

FAHN, A. 1990. Plant anatomy. $4^{\text {th }}$ ed. Pergamon Press, New York.

FEDER, N. \& O'BRIEN, T.P. 1968. Plant microtechnique: some principles and new methods. American Journal of Botany 55:123-142.

GABRIEL, B.L. 1982. Biological Electron Microscopy. Nostrand Reinhold Company, New York.

GENTRY, A.H. 1992. Bignoniaceae - Part II (Tribe Tecomeae). Flora Neotropica. Monograph 25:1-370.

GHATAK, J. 1956. A contribution to the life-history of Oroxylum indicum Vent. Proceedings of the Indian Academical Science 43 B:72-87.

GIBBS, P.E. \& BIANCHI, M. 1993. Post-polination events in species of Chorisia (Bombacaceae) and Tabebuia (Bignoniaceae) with late-acting self-incompatibility. Botanica Acta 106:64-71.

GOLDENBERG, R. \& SHEPHERD, G. 1998. Studies on the reproductive biology of Melastomataceae in "cerrado" vegetation. Plant Systematics and Evolution 211:13-29.

GROSSNIKLAUS, U., KOLTUNOW, A. \& VAN LOOKEREN-CAMPAGNE, M. 1998. A bright future for apomixis. Trends in Plant Science 3:415-416.

GUPTA, P., SHIVANNA, K.R. \& MOHAN RAM, H.Y. 1996. Apomixis and polyembryony in the guggul plant, Commiphora wightii. Annals of Botany 78:67-72.

JOHANSEN, D.A. 1940. Plant microtechenique. Mc GrawHill Book Company, New York.

JOHANSEN, D.A. 1950. Plant Embryology: embryogeny of the Spermatophyta. Waltham, Massachusettes.

JOHRI, B.M. 1984. Embryology of Angiosperms. Springer Verlag, Berlin.

JOHRI, B.M., AMBEGAOKAR, K.B. \& SRIVASTAVA, P.S. 1992. Comparative embryology of Angiosperms. Springer Verlag, Berlin.

KOLTUNOW, A.M., SOLTYS, K., NITO, N. \& MCCLURE, S. 1995. Anther, ovule, seed, and nucellar embryo development in Citrus sinensis cv. Valencia. Canadian Journal of Botany 73:1567-1582.

MAHESHWARI, P. 1950. An Introduction to the Embryology of Angiosperms. Tata McGraw-Hill, New Dehli.

MEHRA, K.R. \& KULKARNI, A.R. 1985. Embryological studies in Bignoniaceae. Phytomorphology 35:239-251.

MENDES-DA-GLÓRIA, F.J., MOURÃO FILHO, F.A.A. \& APPEZZATO-DA-GLÓRIA, B. 2001. Morfologia de embriões nucelares de laranja 'valência' (Citrus sinensis (L.) Osbeck). Acta Botanica Brasilica 15:17-25.

OLIVEIRA, P.E., GIBBS, P.E., BARBOSA, A.A. \& TALAVERA, S. 1992. Constrasting breeding systems in two Eriotheca (Bombacaceae) species of the Brazilian cerrados. Plant Systematics and Evolution 179:207-219. 
PIAZZANO, M. 1998. Números cromosómicos en Bignoniaceae de Argentina. Kurtziana 26:179-189.

RICHARDS, A.J. 1997. Plant breeding system. $2^{\text {nd }}$ ed. George Allen \& Unwin, London.

SALOMÃO, A.N. \& ALLEM, A.C. 2001. Polyembryony in angiospermous trees of the brazilian cerrado and caatinga vegetation. Acta Botanica Brasilica 15:369-378.

SOUĖGES, R. 1940. Embryogénie des Bignoniacées. Développement de l'embryon chez le Catalpa kaempferi Sieb. et Zucc. Comptes Rendus Academie des Sciences 210:116-118.
SWAMY, B.G.L. 1941. Contribuitions to the life history of Bignonia megapotamica. Journal of the Indian Botanical Society 20:299-305.

SWAMY, B.G.L. 1948. Agamospermy in Spiranthes cernua. Lloydia 11:149-162.

TILTON, V.R. 1980. Hypostase development in Ornithogalum caudatum (Liliaceae) and notes on other types of modifications in the chalaza of angiosperm ovules. Canadian Journal of Botany 58:2059-2066.

VAN BAARLEN, P., VERDUIJN, M. \& VAN DIJK, P.J. 1999. What can we learn from natural apomitics? Trends in Plant Science 4:43-44. 